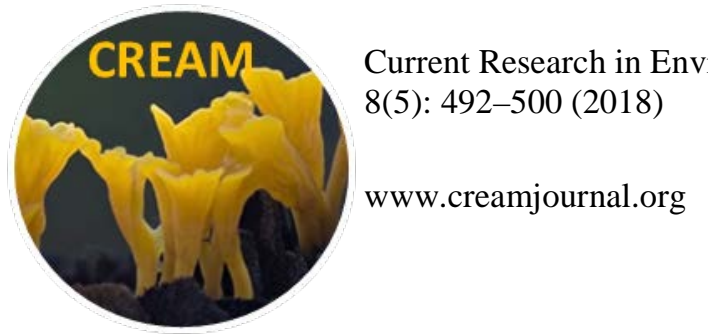

ISSN 2229-2225

\title{
Predicting local habitat suitability in changing climate scenarios: Applying species distribution modelling for Diderma hemisphaericum
}

\author{
Almadrones-Reyes KJ ${ }^{1{ }^{*}}$ and Dagamac NHA ${ }^{2}$ \\ ${ }^{1}$ Advanced Education Program, Thai Nguyen University of Agriculture and Forestry, Thai Nguyen City, Thai Nguyen \\ Vietnam \\ ${ }^{2}$ Institute of Botany and Landscape Ecology, University of Greifswald, Soldmannstr. 15. D-17487, Greifswald, \\ Germany
}

Almadrones-Reyes KJ, Dagamac NHA 2018 - Predicting local habitat suitability in changing climate scenarios: Applying species distribution modelling for Diderma hemisphaericum. Current Research in Environmental \& Applied Mycology (Journal of Fungal Biology) 8(5), 492-500, Doi 10.5943/cream/8/5/2

\begin{abstract}
Over the past few decades, myxomycete research in the Philippines has focused mainly on diversity and systematics studies. As an important player in forest ecosystem, cosmopolitan species like Diderma hemisphaericum can serve as an ideal organism to be modelled for species distribution. Hence, this study was conducted where available species occurrence data of $D$. hemisphaericum in the Philippines and environmental layers for bioclimatic predictors were subjected in the MaxEnt software to give a predictive current distribution and probable distribution of the species under two changing climate scenarios (A2 and B1). The models show wider spread of the species over the influence of two most important bioclimatic variables, namely isothermality and temperature seasonality. Moreover, the models suggested areas where the species could potentially flourish and calls for possible conservation strategies for those areas that are locally facing threat of habitat loss and rapid deforestation caused by growing urbanization. This is the first report of local species distribution modelling for the Philippines and the whole Southeast Asia.
\end{abstract}

Key words - climate change - environmental niche - fungus-like protist - forest management percent contribution - permutation importance

\section{Introduction}

Many modern technologies are applied for conservation purposes as we are experiencing an era that deals with what we call climate change. A common trend is modelling the species distribution of an organism (Guisan \& Thuiller 2005). Most of these species distribution modelling (SDM) techniques are found to be comprehensible since they need only two important components, namely (i) the occurrence data or the dataset where the species are reported to be present and (ii) environmental layers (Pearson 2010). Models then utilize the associations between the two components to give an impression about the most probable environmental conditions where the populations of that particular species can be retained. One of the most common approaches is distinguishing the environmental factors in which the species are suitable to flourish and then recognizing where habitable environments are distributed to estimate their geographical distribution (Elith \& Leathwick 2009). There are two principles of environmental conditions used for modelling 
- mechanistic and correlative. The former model has a more complicated understanding because it requires the knowledge of the physiological response of a particular species relative to the environmental factors (e.g., Kearney \& Porter 2009), while the latter model can yield more productive results because only the known occurrence records combined with the environmental variables are used to determine the effects on the rate of species persistence (Rode \& Lieberman 2005, Graham et al. 2004).

In spite of the many promising applications of SDM, only a very limited number of studies have applied it to microbial groups. So far, studies in lichens (see Dymytrova et al. 2016, Braidwood \& Ellis 2012), ectomycorrhizal fungi (see Guo et al. 2017, Wolfe et al. 2010), protosteloid amoebae (Aguilar \& Lado 2012) or insect viruses (see Larson et al. 2010) have applied SDM to address some ecological questions. In the case of the myxomycetes, only few papers have been published that utilizes SDM. Rojas et al. (2015) used this modelling technique to get a better understanding of the five most commonly occurring species of myxomycetes in Costa Rica. In addition, to further prove the speculation about moderate endemicity among myxomycetes, SDM was also used in studies of species such as Badhamia melanospora (Aguilar et al. 2014) and Hemitrichia serpula (Dagamac et al. 2017a).

Studies of myxomycetes in the Philippines have been going on during the last five decades and thus far most of the information is concentrated on lowland diversity studies of many forest habitats in the country (Dagamac \& dela Cruz 2015). An ideal myxomycete species that can serve as a flagship model to begin a local species distribution modelling in the Philippines would be Diderma hemisphaericum (Bull.) Hornem. since this species is the most common myxomycete that has appeared in most systematics surveys conducted in the Philippines (see Macabago et al. 2017, Pecundo et al. 2017, Dagamac et al. 2015a, b) . Moreover, there is relatively little information about the local distribution of this species in the Philippines due to the fact that most occurrence data that are currently available are coming only from extensive studies in selected northern islands of the country. Thus, to address this predicament, the following research questions were formulated: (i) What are the other possible areas or suitable habitats in the Philippine archipelago where $D$. hemisphaericum can be found using the maximum entropy algorithm? (ii) How would be the predictive local distribution of $D$. hemisphaericum differ after subjecting them to two (A2 and B1) different climate change scenarios?

\section{Materials \& Methods}

\section{Gathering the distribution records of $D$. hemisphaericum in the Philippines}

Initially, all published literatures about the distribution and diversity of Philippine myxomycetes were surveyed. From these studies (see Carascal et al. 2017, Macabago et al. 2017, Dagamac et al. 2017b, c, Pecundo et al. 2017, Rea-Maminta et al. 2015, Dagamac et al. 2015a, b, Viray et al. 2014, dela Cruz et al. 2014, Kuhn et al. 2013, Dagamac et al. 2012, Macabago et al. 2012, Dagamac et al. 2011, dela Cruz et al. 2011), only those that (i) reported the presence of Diderma hemisphaericum and (ii) annotated a valid coordinate of the locality where $D$. hemisphaericum was found were used for the analysis. Overall, 46 coordinates that recorded the occurrences of Diderma hemisphaericum from the Philippines were used for this research framework. The valid coordinates were considered now as a presence-only input file (species occurrence data) with negligible sampling bias with respect to sampling conditions. The input files were converted into geographic coordinate system (latitude and longitude) format and was then saved as a comma delimited or CSV file type.

\section{Obtaining current and future (A2 and B1) environmental layers}

In this study, two different environmental scenarios, which in this case, the 19 bioclimatic variables, in the Philippines were used: (i) the current climate (for the period of 1950-2000) at 2.5' resolution, which can be obtained in the PhilGIS web portal (http://ww.philgis.org) (see also Hijmans et al. 2005), and (ii) A2 and B1 climate scenarios for the year of 2080, which can be 
downloaded in (http://www.ccafs-climate.org) following Banag et al. (2015) protocol. These two future scenarios (A2 and B1) were chosen because they represent two different storylines of climate change. The A2 scenario assumes a continuously growing population and higher emission rate with a global mean temperature forecasted to rise by $3.4^{\circ}$ Celsius. On the contrary, the B1 scenario assumes a change in material use and technology advances in a more efficient way; as such, it predicts that the global mean temperature will increase by only $1.8^{\circ}$ Celsius. These two future scenarios were downloaded as an ESRI file and were then converted to ASCII format to match the requirements in the MaxEnt software.

\section{Species distribution modelling}

The species occurrence data that was transformed as a presence-only input file of Diderma hemisphaericum and (19) bioclimatic variable for the local region of the Philippines were modelled using MaxEnt v. 3.4.1 (http://biodiversityinformatics.amnh.org/open_source/maxent/). MaxEnt is an open-source software that is used for modelling species niche and distribution that utilizes machine-learning based on maximum entropy algorithm (Phillips et al. 2004). Typically, MaxEnt software is applied for conservation purposes (Yang et al. 2013, Kumar \& Stohlgren 2009, Thorn et al. 2009) because it provides more accurate predictions than any other species distribution modelling algorithm (Townsend-Peterson et al. 2007). Furthermore, MaxEnt create better predictions even though the sample size (species occurrence data) is relatively small (Costa et al. 2010). Herein, the two datasets (1) species occurrence data and (2) bioclimatic variables were subjected in the MaxEnt software using the default settings. Furthermore, the option "Create a response curve" and "Do jackknife test to measure variable importance" were ticked and then the output format was set to "logistic" in order to evaluate the importance of each biophysical variable. The output file that was generated from MaxEnt was then exported as ASCII file format. To get a detailed visualization, the ASCII output file format from MaxEnt was imported in ArcMap 10.4 software. In the ArcMap software, the map was then divided using defined interval as a classification method into four different categories.

\section{Results}

The maximum entropy algorithm used for species distribution modelling for Diderma hemisphaericum suggested different important bioclimatic variables that probably influence the predictive local distribution of this species in the Philippines. Taking into consideration the measure of percent contribution, both for the current predictive distribution and A2 climate scenario, isothermality has the highest percentage contribution with 41.3 , and 29.3, respectively, but for the B1 climate scenario the highest contribution was attributed to temperature seasonality (23.6\%). In terms of permutation importance, the model calculation indicated isothermality to be highest in the current scenario with 47.7 and temperature seasonality for both the future climate change scenarios with 41.2 for the A2 scenario and 28.9 for the B1 scenario. Moreover, the Area Under the Curve (AUC) values from the maximum entropy-based results for the different climatic scenarios are (i) 0.80 for the current climate scenario; (ii) 0.90 for the A2 climate scenario; and (iii) 0.88 for B2 climate scenario which point to a good quality of predictive model performance (Table 1). Furthermore, a Jackknife test revealed that the predictor temperature seasonality contained the most information among the 19 bioclimatic variables for creating the models for the current distribution and two changing climate scenarios. The predictive model (Fig. 1) based on the current species occurrence data recommended areas in the Philippines where the bioclimatic conditions are favorable for $D$. hemisphaericum. A high probability of finding the species is in the areas of Southern Luzon, in particular in Region IV-A (CALABARZON) and the coastal provinces of the Central Luzon Region (Zambales and Bataan). In terms of the distribution of D. hemisphaericum under future changing climate scenarios, the models (Fig. 1) showed that there will be a wider scattering in the distribution of $D$. hemisphaericum. In spite of this, contrasting areas where $D$. hemisphaericum can possibly occur was forecast by the model. In the Luzon Island, somewhat high probability of occurrences under the B1 scenario but a very low probability for the A2 scenario is 
predicted in areas in the northernmost part the Luzon Island (Cagayan). For the scattered islands of Visayas, the B1 scenario will have wider areas around Cebu where D. hemisphaericum can be potentially found, while A2 scenario will have high probability in the southwestern areas of Bohol. Areas in the southernmost part of Sarangani in Mindanao are expected to have moderately high chances of $D$. hemisphaericum incidence for the A2 scenario but very low chances for the B1 scenario.

Table 1 Number of species occurrence record used for the models, AUC-Values, percentage contribution, permutation importance and training gain (with and without respective variable) for the 5 most contributory predictors

\begin{tabular}{|c|c|c|c|c|c|c|c|}
\hline & $\begin{array}{l}\text { No. of } \\
\text { records }\end{array}$ & $\begin{array}{l}\text { AUC } \\
\text { (Test) }\end{array}$ & 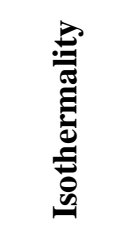 & 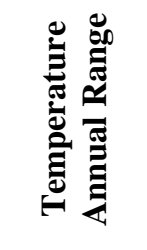 & 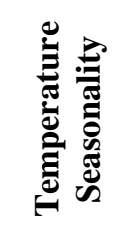 & 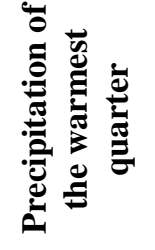 & 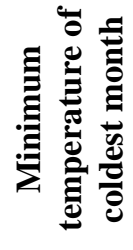 \\
\hline Current & 46 & 0.80 & & & & & \\
\hline Contribution (\%) & & & 41.30 & 21.20 & 13.70 & 7.00 & 4.90 \\
\hline Perm. Importance & & & 47.70 & 18.40 & 8.10 & 0.20 & 2.70 \\
\hline Training gain without & & & 1.30 & 1.25 & 1.34 & 1.31 & 1.35 \\
\hline \multirow[t]{2}{*}{ Training gain with only } & & & 0.75 & 0.39 & 0.70 & 0.18 & 0.18 \\
\hline & $\begin{array}{l}\text { No. of } \\
\text { records }\end{array}$ & $\begin{array}{l}\text { AUC } \\
\text { (Test) }\end{array}$ & 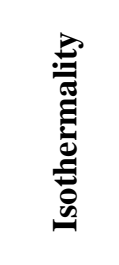 & 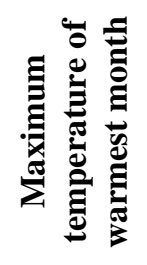 & 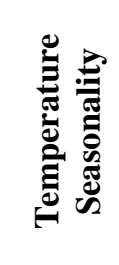 & 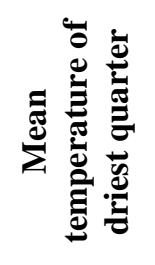 & 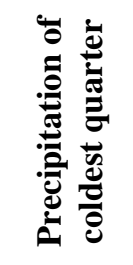 \\
\hline A2 scenario & 46 & 0.90 & & & & & \\
\hline Contribution (\%) & & & 29.30 & 17.90 & 10.20 & 9.50 & 8.40 \\
\hline Perm. Importance & & & 24.30 & 0.00 & 41.20 & 3.30 & 4.30 \\
\hline \multirow{2}{*}{$\begin{array}{l}\text { Training gain without } \\
\text { Training gain with only }\end{array}$} & & & $\begin{array}{l}1.25 \\
0.48\end{array}$ & $\begin{array}{l}1.25 \\
0.52\end{array}$ & $\begin{array}{c}11.19 \\
0.66\end{array}$ & $\begin{array}{l}1.22 \\
0.18\end{array}$ & $\begin{array}{l}1.23 \\
0.34\end{array}$ \\
\hline & $\begin{array}{l}\text { No. of } \\
\text { records }\end{array}$ & $\begin{array}{l}\text { AUC } \\
\text { (Test) }\end{array}$ & 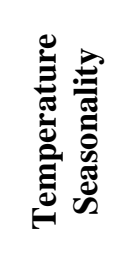 & 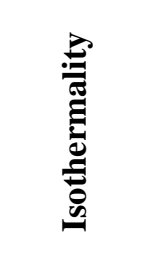 & 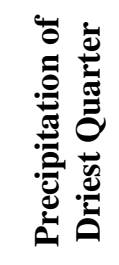 & 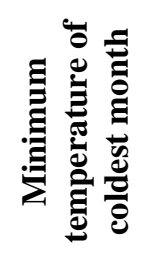 & 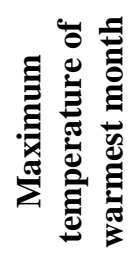 \\
\hline B1 scenario & 46 & 0.88 & & & & & \\
\hline Contribution (\%) & & & 23.60 & 15.70 & 13.70 & 10.40 & 7.70 \\
\hline Perm. Importance & & & 28.90 & 0.60 & 7.60 & 19.80 & 0.00 \\
\hline Training gain without & & & 0.93 & 1.19 & 1.16 & 1.13 & 1.19 \\
\hline Training gain with only & & & 0.81 & 0.51 & 0.50 & 0.25 & 0.39 \\
\hline
\end{tabular}

AUC values are threshold-independent model quality standard for that ranges between 0 (no fitness) - 1 (perfect fitness). Only the model that gives values above 0.70 is considered to be valuable models. Training gains are based on the result of the Jackknife test for the specific variable in isolation (training gain with only) and exclusion (training gain without). 


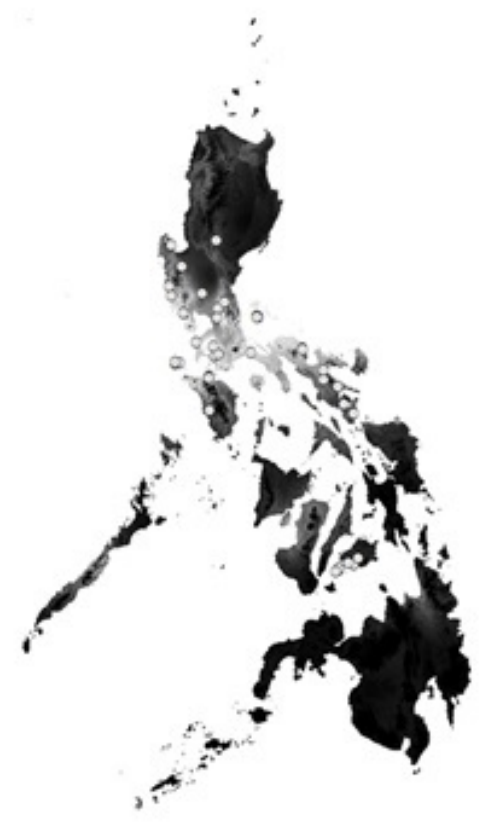

Diderma

hemisphaericum local distribution

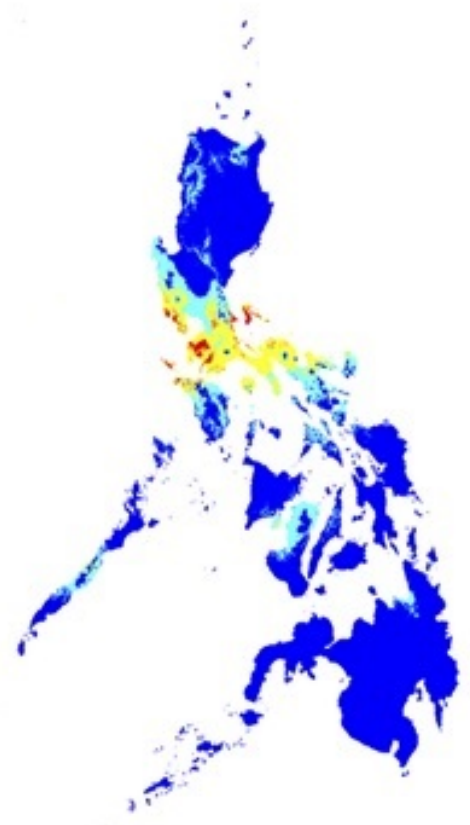

Current Climate

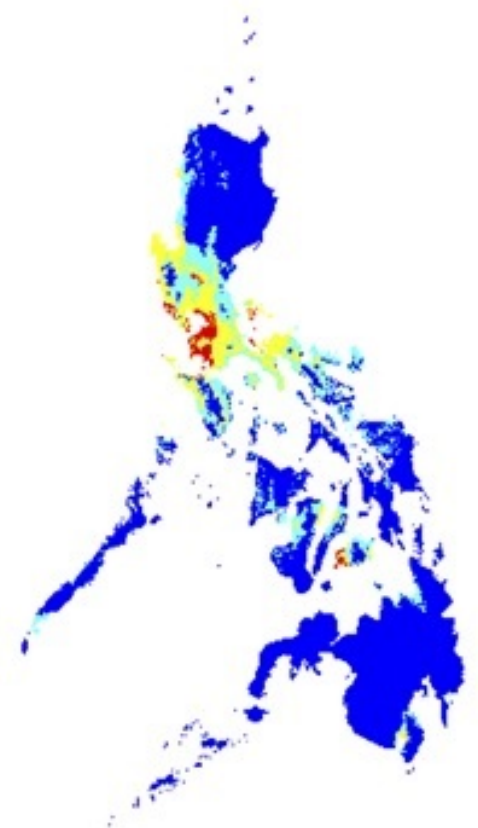

A2 Climate Scenario

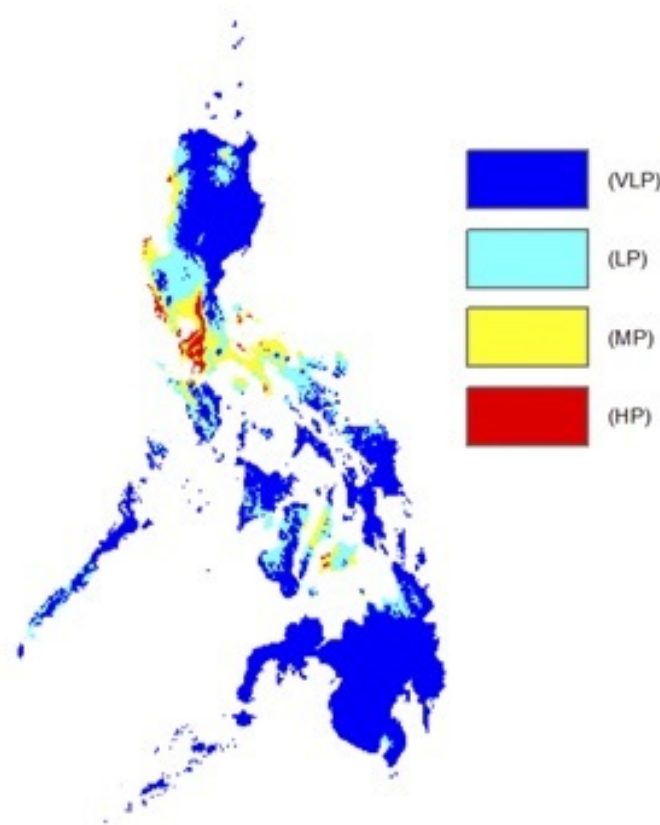

\section{B1 Climate \\ Scenario}

Fig. 1 - Species distribution models for Diderma hemisphaericum showing map of the Philippines and the predictive suitable habitat areas (based from the probability of presence-only input files) under current conditions and two future changing climate scenarios for the year 2080 generated by maximum entropy algorithm. The circle on the local distribution maps indicates the locations based on the published geographic coordinates of species occurrences where $D$. hemisphaericum were recorded. The next three maps were pictured on a heat map based on the yielded chance of occurrence for $D$. hemisphaericum. Blue indicates very low probability (VLP) which values range from $0-\leq 0.25$, cyan indicates low probability (LP) which range from $>0.25-\leq 0.50$, yellow indicates medium probability (MP) which values range from $>0.50-\leq 0.75$ and red indicates high probability (HP) which values range from $>0.75-1.00$. 


\section{Discussion}

Among the bioclimatic variables tested for the local distribution of Diderma hemisphaericum in the Philippines, isothermality and temperature seasonality predictors have the highest contribution for the three models (Table 1). Moreover, the high AUC values obtained for each model, which ranged from 0.80 to 0.90 indicate strong accuracy of the predictive tests (Phillips et al. 2006). On one hand, isothermality can be very useful in insular, maritime and tropical environment (Nix 1986) such as the Philippines because the species could be influenced by temperature fluctuations. A similar case from the environmental niche modelling of some Costa Rican myxomycetes also found that isothermality has the highest contributing factors and was suggested that this predictor could be directly influencing the life cycle of tropical myxomycetes species (Rojas et al. 2015). On the other hand, the predictor temperature seasonality, refers to the temperature change over the year (O’Donell et al., 2012), also has an important factor in the predicted distribution of $D$. hemisphaericum. Several studies in Southeast Asia (Philippines, Dagamac et al. 2012, Thailand, Ko Ko et al. 2011) attempted to associate seasonality with myxomycete diversity. These studies showed that the variations in the amount of successful fruiting between dry and wet seasons usually experienced in the tropics. However, it is recommended that to ascertain the association of isothermality and temperature seasonality with myxomycetes development, particularly with the cosmopolitan $D$. hemisphaericum, more systematic studies and a controlled experimentation set-up are needed to validate such claims.

The maximum entropy-based modelling is based on presence-only and background data (Merow et al. 2013) that can make accurate predictions even when there is a low sample size as low as three for narrow-ranged and 13 for widespread species (Proosdij et al. 2016), thus making it the most appropriate algorithm for this case study of $D$. hemisphaericum. This is the case on how the models selected the expansion of possible suitable ranges of habitat in the three major islands of the Philippine archipelago. However, it is important to note that the predictive model generated by this study for $D$. hemisphaericum relies heavily only on those data for abiotic factors and does not include possible biotic interactions such as dispersal, predation and species mobility. Furthermore, it is necessary to know that the models have more predictive tests on species distribution in the main island of Luzon due to the fact that most of the species occurrence data has been gathered from this region thus, like every species distribution models (see studies of Abdou et al. 2016, Aguilar et al. 2014), it should be treated with a caveat (Sinclair et al. 2010). Since in the current investigations of myxomycetes in the Philippines, no records apparently have been reported in Mindanao, hence very low probability was predicted in most areas of those islands. It is therefore recommended to start doing biodiversity assessments in many forested habitat in the country particularly on those areas.

In fact, knowledge about fundamental niches for many Philippine species is still missing, especially for the myxomycetes. This kind of study can help understand the potential distribution patterns of Diderma hemisphaericum that can provide baseline information and serve as a great model for better conservation strategies in many terrestrial ecosystems in the country. The predictive models suggested a high probability and wider distribution in the future; however, several factors like deforestation, land-use change, and urbanization, that have been currently happening on most of the predicted suitable habitats (e.g., Cebu, Sarangani, National Capital Region) can drastically affect species distribution. Therefore, it is necessary to establish different measures to conserve the habitats on the areas where $D$. hemisphaericum would suitably thrive. With that said, this study was carried out with the hope of shedding light on many priority areas that need to be protected using fungal biota as model for Philippine biodiversity.

\section{Acknowledgements}

KJA-R and NHAD is grateful to Prof. Martin Schnittler and the International Office (University of Greifswald) for the financial support given during the course of this study. We also would like to acknowledge the reviewers who helped improve the version of this paper. 


\section{References}

Abdou L, Diouf A, Inoussa MM, Mamoudou BM et al. 2016 - Modelling the Geographic Distribution of Prosopis africana (G. and Perr.) Taub. in Niger. Environment and Natural Resources Research, 6(2), 136-144.

Aguilar M, Lado C. 2012 - Ecological niche models reveal the importance of climate variability for the biogeography of protosteloid amoebae. The ISME journal, 6(8), 1506- 1514.

Aguilar M, Fiore-Donno AM, Lado C, Cavalier-Smith T. 2014 - Using environmental niche models to test the 'everything is everywhere' hypothesis for Badhamia. The ISME Journal, 8(4), 737-745.

Banag C, Thrippleton T, Alejandro GJ, Reineking B, Liede-Schumann S. 2015 - Bioclimatic niches of selected endemic Ixora species on the Philippines: predicting habitat suitability due to climate change. Plant Ecology, 216(9), 1325-1340.

Braidwood D, Ellis CJ. 2012 - Bioclimatic equilibrium for lichen distributions on disjunct continental landmasses. Botany, 90(12), 1316-1325.

Carascal MB, dela Cuz TEE, Rea MAD, Dagamac NHA. 2017 - Myxomycetes associated with grassland litter in the Philippines. Current Research in Environmental and Applied Mycology, $7(2), 56-63$.

Costa GC, Nogueira C, Machado RB, Colli GR. 2010 - Sampling bias and the use of ecological niche modelling in conservation planning: a field evaluation in a biodiversity hotspot. Biodiversity and Conservation, 19(3), 883-899.

Dagamac NHA, dela Cruz TEE. 2015 - Myxomycete research in the Philippines: Updates and opportunities. Mycosphere, 6(6), 784-795.

Dagamac NHA, dela Cruz TEE, Pangilinan MVB, Stephenson SL. 2011 - List of species collected and interactive database of myxomycetes (plasmodial slime molds) for Mt. Arayat National Park, Pampanga, Philippines. Mycosphere, 2(4), 449-455.

Dagamac NHA, Rojas C, Novozhilov YK, Moreno GH et al. 2017a - Speciation in progress? A phylogeographic study among populations of Hemitrichia serpula (Myxomycetes). PloS one, 12(4), e0174825.

Dagamac NHA, dela Cruz TEE, Rea-Maminta MAD, Cruz AD, Jeane V, Schnittler M. 2017b Rapid assessment of myxomycete diversity in the Bicol Peninsula, Philippines. Nova Hedwigia, 104(1-2), 31-46.

Dagamac NHA, Novozhilov YK, Stephenson SL, Lado C et al. 2017c - Biogeographical assessment of myxomycete assemblages from Neotropical and Asian Palaeotropical forests. Journal of Biogeography, 44(7), 1524-1536.

Dagamac NHA, Rea-Maminta MAD, Batungbacal NS, Jung SH et al. 2015a - Diversity of plasmodial slime molds (myxomycetes) in coastal, mountain, and community forests of Puerto Galera, Oriental Mindoro, the Philippines. Journal of Asia-Pacific Biodiversity, 8(4), 322-329.

Dagamac NHA, Rea-Maminta MAD, dela Cruz TEE. 2015b - Plasmodial slime molds of a tropical karst forest, Quezon National Park, the Philippines. Pacific Science, 69(3), 411-422.

Dagamac NHA, Stephenson SL, dela Cruz TEE. 2012 - Occurrence, distribution and diversity of myxomycetes (plasmodial slime moulds) along two transects in Mt. Arayat National Park, Pampanga, Philippines. Mycology, 3(2), 119-126.

dela Cruz TEE, Kuhn RV, Javier AOM, Rodillas CP et al. 2011 - Occurrence and distribution of plasmodial myxomycetes in Hundred Islands National Park, Pangasinan, Philippines. Acta Manilana, 59, 65-74.

dela Cruz TEE, Rea M, Tran H, Ko Ko T, Stephenson S. 2014 - A comparative species listing of myxomycetes from tropical (Philippines) and temperate (United States) forests Mycosphere, 5(2), 299-311.

Dymytrova L, Stofer S, Ginzler C, Breiner FT, Scheidegger C. 2016 - Forest-structure data improve distribution models of threatened habitat specialists: Implications for conservation of epiphytic lichens in forest landscapes. Biological Conservation, 196, 31-38. 
Elith J, Leathwick JR. 2009 - Species distribution models: Ecological explanation and prediction across space and time. Annual Review of Ecology, Evolution, and Systematics, 40, 677-697.

Graham CH, Ron SR, Santos JC, Schneider CJ, Moritz C. 2004 - Integrating phylogenetics and environmental niche models to explore speciation mechanisms in dendrobatid frogs. Evolution, 58(8), 1781-1793.

Guisan A, Thuiller W. 2005 - Predicting species distribution: offering more than simple habitat models. Ecology letters, 8(9), 993-1009.

Guo Y, Li X, Zhao Z, Wei H et al. 2017 - Prediction of the potential geographic distribution of the ectomycorrhizal mushroom Tricholoma matsutake under multiple climate change scenarios. Scientific reports, 7, 46221.

Hijmans RJ, Cameron SE, Parra JL, Jones PG, Jarvis A. 2005 - Very high resolution interpolated climate surfaces for global land areas. International Journal of Climatology, 25(15), 19651978.

Kearney M, Porter W. 2009 - Mechanistic niche modelling: combining physiological and spatial data to predict species' ranges. Ecology Letters, 12(4), 334-350.

Ko Ko TW, Stephenson SL, Hyde KD, Lumyong S. 2011 - Influence of seasonality on the occurrence of myxomycetes. Chiang Mai Journal of Science, 38, 71-84.

Kuhn RV, Javier AOM, Rodillas CP, Parra CM et al. 2013 - Diversity of plasmodial myxomycetes from Anda Island, Pangasinan, Philippines. Biotropia, 20(1), 1-9.

Kumar S, Stohlgren TJ. 2009 - Maxent modelling for predicting suitable habitat for threatened and endangered tree Canacomyrica monticola in New Caledonia. Journal of Ecology and the Natural Environment, 1(4), 94-98.

Larson SR, Degroot JP, Bartholomay LC, Sugumaran R. 2010 - Ecological niche modelling of potential West Nile virus vector mosquito species in Iowa. Journal of Insect Science, 10(1), 110.

Macabago SAB, Dagamac NHA, dela Cruz TEE, Stephenson SL. 2017 - Implications of the role of dispersal on the occurrence of litter-inhabiting myxomycetes in different vegetation types after a disturbance: a case study in Bohol Islands, Philippines. Nova Hedwigia, 104(1-3), 221-236.

Macabago SAB, dela Cruz TEE, Stephenson SL. 2012 - First records of myxomycetes from Lubang Island, Occidental Mindoro, Philippines. Sydowia, 64(1), 109-118.

Merow C, Smith MJ, Silander Jr JA. 2013 - A practical guide to MaxEnt for modelling species' distributions: what it does, and why inputs and settings matter. Ecography, 36(10), 10581069.

Nix HA. 1986 - A biogeographic analysis of Australian elapid snakes. Atlas of Elapid Snakes of Australia, 7, 4-15.

Pearson RG. 2010 - Species distribution modelling for conservation educators and practitioners. Lessons in Conservation, American Museum of Natural History, 3, 54-89.

Pecundo MH, Dagamac NHA, Stephenson SL, dela Cruz TEE. 2017 - First myxomycete survey in the limestone forest of Puerto Princesa Subterranean River National Park, Palawan, Philippines. Nova Hedwigia, 104(1-3), 129-141.

Phillips SJ, Anderson RP, Schapire RE. 2006 - Maximum entropy modelling of species geographic distributions. Ecological modelling, 190(3-4), 231-259.

Phillips SJ, Dudík M, Schapire RE. 2004 - A maximum entropy approach to species distribution modelling. In Proceedings of the twenty-first international conference on Machine learning (p. 83). ACM.

Proosdij AS, Sosef MS, Wieringa JJ, Raes N. 2016 - Minimum required number of specimen records to develop accurate species distribution models. Ecography, 39(6), 542-552.

Rea-Maminta MAD, Dagamac NHA, Huyop FZ, Wahab RA, dela Cruz TEE. 2015 - Comparative diversity and heavy metal biosorption of myxomycetes from forest patches on ultramafic and volcanic soils. Chemistry and Ecology, 31(8), 741-753. 
Rode ALS, Lieberman BS. 2005 - Using environmental niche modelling to study the Late Devonian biodiversity crisis. In Developments in Palaeontology and Stratigraphy (Vol. 20, pp. 93-179). Elsevier.

Rojas C, Zuñiga JM, Stephenson SL. 2015 - Ecological niche modelling of some Costa Rican myxomycetes. Current Research in Environmental and Applied Mycology, 5, 153-159.

Sinclair SJ, White MD, Newell GR. 2010 - How useful are species distribution models for managing biodiversity under future climates? Ecology and Society, 15(1), 8.

Thorn JS, Nijman V, Smith D, Nekaris KAI. 2009 - Ecological niche modelling as a technique for assessing threats and setting conservation priorities for Asian slow lorises (Primates: Nycticebus). Diversity and Distributions, 15(2), 289-298.

Townsend-Peterson A, Papeş M, Eaton M. 2007 - Transferability and model evaluation in ecological niche modelling: a comparison of GARP and Maxent. Ecography, 30(4), 550-560.

Viray AT, Rotap DDS, Migraso LL, Sibbaluca NCI et al. 2014 - Occurrence and diversity of myxomycetes (slime molds) in Polillo Island, Quezon Province, Philippines. Acta Manilana, 62, 9-17.

Wolfe BE, Richard F, Cross HB, Pringle A. 2010 - Distribution and abundance of the introduced ectomycorrhizal fungus Amanita phalloides in North America. New Phytologist, 185(3), 803-816.

Yang XQ, Kushwaha SPS, Saran S, Xu J, Roy PS. 2013 - Maxent modelling for predicting the potential distribution of medicinal plant, Justicia adhatoda L. in lesser Himalayan foothills. Ecological Engineering, 51, 83-87. 